\title{
Gastro-oesophageal reflux in mechanically ventilated preterm infants
}

\author{
L Pradeaux, V Boggio, J B Gouyon
}

\begin{abstract}
Long duration oesophageal pH recordings were performed on 42 mechanically ventilated and parenterally fed preterm infants for a mean (SD) of 94 (28) hours. Their mean (SD) gestational age was $31.5(2.6)$ weeks and birth weight $1514(448) \mathrm{g}$. Their mean postnatal age was 19 (10) hours at the onset of $\mathrm{pH}$ recording, which was performed with the babies supine. The mean hourly values for the total number of episodes of gastro-oesophageal reflux (GOR) was $2 \cdot 3(2 \cdot 7)$, for acid GOR 1.2 (1.4), and for acid GOR longer than 5 minutes $0.08(0.09)$. The time the $\mathrm{pH}$ was $>4$ (the reflux index) was $3.5(3.3) \%$ and the mean airway pressure was $6.6(5 \cdot 1) \mathrm{cm} \mathrm{H}_{2} \mathrm{O}$. Fifteen infants had a reflux index above $5 \%$. GOR patterns were not significantly correlated to birth weight, gestational age, postconceptional age, ventilatory patterns, and duration of mechanical ventilation. We concluded that the reproducibility of the reflux index was low because the median of the absolute differences was $1 \%$ when two consecutive 12 hour periods were compared and reached $2.5 \%$ when the two periods were separated by 96 hours.
\end{abstract}

A second 24 hour pH recording was performed in 30 of the $\mathbf{4 2}$ patients after weaning from the ventilator and at a time when patients were asymptomatic and enterally fed. Compared with the late postprandial period of the second pH recording, the first recording showed an increase in the number of episodes of GOR and a decrease in reflux index, without any difference in the number of episodes of acid GOR.

Endotracheal aspiration of pharyngeal ${ }^{1}$ or gastric contents ${ }^{2}$ is a frequent event in mechanically ventilated newborn infants. A role for this phenomenon in the pathogenesis of bronchopulmonary dysplasia has been strongly suggested but still remains under investigation. ${ }^{3} \mathrm{~A}$ high incidence in gastro-oesophageal reflux (GOR) has been demonstrated in ventilated adult patients ${ }^{4}$ but limited data have failed to show similar findings in nine mechanically ventilated preterm infants. ${ }^{5}$ Therefore, the purpose of this prospective study was to assess the patterns of prolonged oesophageal $\mathrm{pH}$ recordings in mechanically ventilated preterm infants.

Patients and methods

From January 1987 to June 1989, 42 mechanically ventilated preterm infants were eligible for the study. The mean (SD) gestational age and birth weight were respectively $31.5(2 \cdot 6)$ weeks (range 26-36 weeks) and 1514 (448) g (range $800-2500 \mathrm{~g})$.

The primary respiratory illnesses requiring intermittent positive pressure ventilation (IPPV) were delayed fetal lung fluid absorption $(n=19)$, severe hyaline membrane disease $(n=$ 9), bacterial respiratory infection $(n=2)$, meconium amniotic fluid aspiration $(n=5)$, pulmonary hypertension $(n=1)$, and hypoventilation associated with central nervous system disorders and hypotonia $(n=6)$. Infants were ventilated either on a pressure cycled ventilator (Drager Babylog 1 and Sechrist infant ventilator IV $100 \mathrm{~B}$ ) or on a volume ventilator (Siemens Servo $900 \mathrm{C}$ ). Positive end expiratory pressure of 2-6 $\mathrm{cm} \mathrm{H}_{2} \mathrm{O}$ was used for all infants on IPPV. The ventilatory patterns may indicate the severity of the underlying pulmonary disease. Therefore, fractional inspiratory oxygen concentration, positive end expiratory pressure (PEEP), positive inspiratory pressure (PIP), and respiratory rate were recorded hourly during the whole duration of $\mathrm{pH}$ recordings. Mean airway pressure (MAP) was calculated according to the formula. ${ }^{6}$ :

$$
\mathrm{MAP}=(\mathrm{I} / \mathrm{E} \times \mathrm{PIP}+\mathrm{PEEP}) /(\mathrm{I} / \mathrm{E}+1)
$$

where $\mathrm{I}$ and $\mathrm{E}$ were respectively the inspiratory and expiratory times.

Infants were nursed in the supine position and routine care included pulmonary physiotherapy, mucus aspiration from the endotracheal tube, blood sampling, nappy changes, and setting of intravenous peripheral infusions. All these procedures were recorded because routine care is associated with significant increases in the amount of GOR. ${ }^{5}$

The oesophageal $\mathrm{pH}$ was recorded using a glass microelectrode (Microelectrode Inc MI 508 , with a $1.2 \mathrm{~mm}$ outer diameter) as previously described. ${ }^{8}$ Briefly, the $\mathrm{pH}$ probe was calibrated with two standard buffered solutions (pH 7.0 and 1.68). The electrode was introduced through the nose and its distal end was placed into the stomach as indicated by a fall in $\mathrm{pH}$ values $(<4)$. The probe was gently withdrawn and a sudden $\mathrm{pH}$ increase indicated the oesophageal positioning of the probe. Thus the distal end of the probe was placed 2 to $3 \mathrm{~cm}$ above the lower oesophageal sphincter. The pH probe placement was confirmed by a daily chest radiograph and the probe was also calibrated each day. A skin electrocardiographic electrode was used as a reference electrode. Both electrodes were connected to a $\mathrm{pH}$ meter (Beckman 3500 ) through a patient isolation unit. The electrical signal was proportional to the $\mathrm{pH}$ and 
was fed into a strip chart recorder (Linear 1201, 4 minutes $/ \mathrm{cm}$, calibration: $1 \mathrm{pH}$ unit $/ 20 \mathrm{~mm}$ ).

Taking into account the possibility of 'nonacid' reflux we computed all GOR defined as a fall in $\mathrm{pH}$ of more than one unit, irrespective of whether or not the $\mathrm{pH}$ fell below $4 .^{89}$ Acid GOR corresponded to a $\mathrm{pH}$ fall below $4 \cdot 0$ during for at least 15 seconds. $^{78}$ The following parameters were measured for acid GOR: the number of episodes/hour, number of episodes of GOR longer than 5 minutes/hour, and the percentage time at $\mathrm{pH}$ below 4 (reflux index).

A first oesophageal $\mathrm{pH}$ recording was started as soon as possible after the onset of mechanical ventilation. This monitoring lasted 120 hours in fasted and mechanically ventilated infants and enteral feedings or weaning from the ventilator ended the recording. No infants received sedation, muscle relaxants, or xanthine derivatives during this oesophageal $\mathrm{pH}$ recording. One infant died on the second day and the 41 remaining infants needed ventilatory support for $15(15 \cdot 5)$ days (range 2.5-58 days).

A second oesophageal $\mathrm{pH}$ recording was performed during 24 hours after weaning from the ventilator at a time when patients were asymptomatic, enterally fed, and did not receive any drug. Thirty of the 42 patients fulfilled these criteria.

Clinical management was constantly assumed by doctors not involved in the study.

\section{STATISTICAL METHODS}

Values were expressed as mean (SD) either for the total duration of the recordings or for each successive 12 hour period of the first recording. Additionally, 10th, 50th, and 90th centiles were calculated for GOR patterns.

The long duration of the first oesophageal $\mathrm{pH}$ recording allowed an assessment of the reproducibility of the results for total number of episodes of GOR and acid GOR and reflux index, the later variable being regarded as particularly informative in neonates as it is in older children and adults. ${ }^{10}$ Each 12 hour period was compared with all the following periods for the three variables and absolute values of the differences was recorded for each infant. Because the time interval between the two periods of the comparison could influence the reproducibility of the $\mathrm{pH}$ recording results were expressed for intervals of 0 hour (two consecutive periods), $12,24,48,36,48,60,72,84$, and 96 hours. Insufficient data precluded valid calculations for time interval above 96 hours.

The data were compared using analysis of variance, the Wilcoxon test, and Fisher's exact test as needed. Pearson's test was used for correlation studies. The level of significance was $0.05 .^{11}$

The protocol was approved by the local research ethical committee and informed consent was obtained from parents.

\section{Results}

FIRST OESOPHAGEAL PH MONITORING

Mean postnatal age at the start of the study and mean duration of the recordings were respectively 19 (10) hours (range 5-55 hours) and 94 (28) hours (range 37-120 hours).

The mean hourly values obtained for the total number of episodes of GOR was $2 \cdot 3(2 \cdot 7)$ (range 0-129), for acid GOR $1 \cdot 2(1 \cdot 4)$ (range 0 7 ), and for acid GOR longer than 5 minutes 0.08 $(0.09)$ (range $0-0.4)$. The reflux index was 3.5 $(3 \cdot 3) \%$ (range $0-12 \cdot 1$ ) and the mean airway pressure $6 \cdot 6(5 \cdot 1) \mathrm{cm} \mathrm{H}_{2} \mathrm{O}$. Fifteen infants had a mean hourly value for reflux index above $5 \%$ (range $5 \cdot 1-12 \cdot 2$ ). The distribution of underlying pulmonary diseases was not significantly different in infants with low or high reflux index: delayed fetal lung absorption 11/8, hyaline membrane disease $6 / 3$, pulmonary bacterial infection $2 / 0$, meconium aspiration syndrome $3 / 2$, pulmonary hypertension $0 / 1$, and central hypoventilation $4 / 2$.

Table 1 summarises the data obtained for each 12 hour period of oesophageal $\mathrm{pH}$ recording. GOR patterns did not significantly vary during the recording. Whatever the 12 hour period GOR patterns did not significantly correlate with birth weight, gestational age, post-

Table 1 Gastro-oesophageal patterns in mechanically ventilated preterm infants. For each 12 hour period infants were included if oesophageal pH monitoring lasted at least nine hours

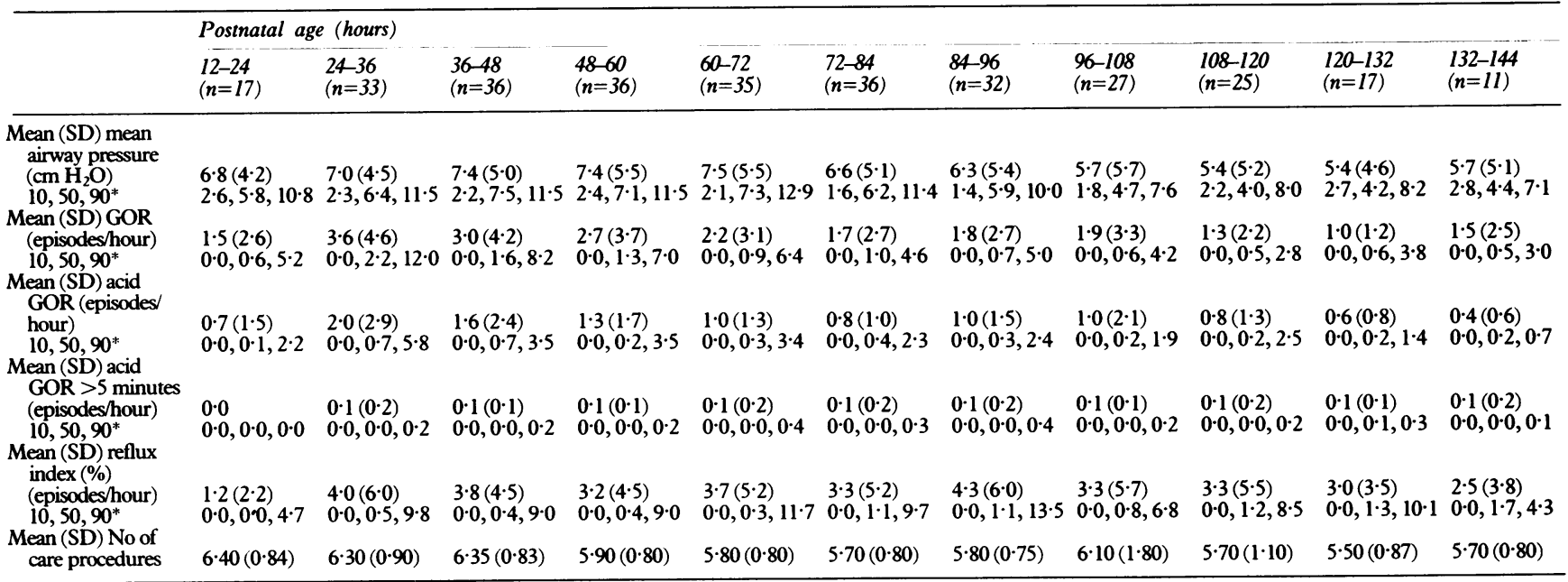

:Results at 10th, 50th, and 90th centiles. 
Table 2 Medians of absolute differences for total number of episodes of GOR and acid GOR and reflux index between 12 hour periods of $\mathrm{pH}$ recording separated by $0,12,24,36$, $48,60,72,84$, and 96 hours

\begin{tabular}{lllll}
\hline $\begin{array}{l}\text { Time (hours) } \\
\text { interval between } \\
\text { the two 12 } \\
\text { hour periods }\end{array}$ & $\begin{array}{l}\text { No of } \\
\text { comparisons }\end{array}$ & $\begin{array}{l}\text { GOR } \\
\text { (episodes/ } \\
\text { hour) }\end{array}$ & $\begin{array}{l}\text { Acid GOR } \\
\text { (episodes/ } \\
\text { hour) }\end{array}$ & $\begin{array}{l}\text { Reflux } \\
\text { index } \\
(\%)\end{array}$ \\
\hline 0 & 252 & 0.55 & 0.30 & 1 \\
12 & 213 & 0.70 & 0.30 & 1.33 \\
24 & 177 & 0.90 & 0.50 & 1.33 \\
36 & 143 & 1.00 & 0.50 & 1.83 \\
48 & 111 & 1.00 & 0.50 & 1.33 \\
60 & 79 & 1.10 & 0.50 & 1.50 \\
72 & 53 & 1.10 & 0.60 & 2.17 \\
84 & 32 & 1.35 & 0.80 & 2.67 \\
96 & 11 & 2.50 & 1.20 & 2.50 \\
\hline
\end{tabular}

Table 3 Comparison between first $\mathrm{pH}$ recording and the late postprandial period of the second $\mathrm{pH}$ recording in 30 infants

\begin{tabular}{|c|c|c|}
\hline & $\begin{array}{l}\text { First pH } \\
\text { recording }\end{array}$ & $\begin{array}{l}\text { Second pH } \\
\text { recording }\end{array}$ \\
\hline $\begin{array}{l}\text { Mean (SD) GOR (episodes/hour) } \\
\text { Mean (SD) acid GOR (episodes/ } \\
\text { hour) } \\
\text { Mean (SD) acid GOR > } 5 \text { minutes } \\
\text { (episodes/hour) } \\
\text { Mean (SD) reflux index (\%) }\end{array}$ & $\begin{array}{l}2.07(2 \cdot 26) \\
1.11(1.06) \\
0.09(0.09) \\
3.70(3.55)\end{array}$ & $\begin{array}{l}1 \cdot 25(0.98)^{*} \\
0.92(0 \cdot 80) \\
0 \cdot 24(0.33) \\
7 \cdot 31(9 \cdot 77)^{*}\end{array}$ \\
\hline
\end{tabular}

conceptional age, ventilatory pattern (PEEP, respiratory rate, mean airway pressure), and total duration of mechanical ventilation. The mean routine care procedures declined slightly but significantly from the first to the last 12 hour period of $\mathrm{pH}$ recording (table 1 ).

Medians for absolute differences from one 12 hour period to the following periods are indicated in table 2 .

SECOND OESOPHAGEAL PH MONITORING

At the time of the second oesophageal $\mathrm{pH}$ monitoring the means for postnatal age, postconceptional age, and weight were respectively 38.4 $(2 \cdot 4)$ days, 6.9 (3) weeks, and 2323 (454) g. At the time of the first recording these 30 patients presented with GOR patterns similar to the whole population (table 3 ).

Taking into account that intragastric $\mathrm{pH}$ is buffered by enteral feedings in the early postprandial period (that is, the first two hours after a meal), ${ }^{8}$ the first $\mathrm{pH}$ recording (without any concomitant enteral feeding) was compared with the late postprandial period of the second pH recording. The first recording presented with an increase in the total number of episodes of GOR without any difference in the number of episodes of acid GOR and a decrease in the reflux index (table 3 ). Reflux index values of the first recording positively correlate with values during the late postprandial period of the second $\mathrm{pH}$ monitoring $(\mathrm{r}=0 \cdot 430, \mathrm{p}=0 \cdot 02)$.

Oesophageal $\mathrm{pH}$ recordings did not cause any side effects.

\section{Discussion}

This study clearly highlights that the first five days of life were associated with a reflux index above $5 \%$ in $36 \%$ of mechanically ventilated preterm infants when they were fasting and in the supine position. A reflux index above $5 \%$ was rarely found in two previous studies conducted in mechanically ventilated preterm infants: in three of 18 infants in the supine position $^{12}$ and one of nine infants in the prone, right lateral, and left lateral position. ${ }^{5}$ In one study the mean for the number of episodes of acid GOR and reflux index appeared lower than in our patients: $0.51(0.11)$ compared with 1.2 $(1.4)$ /hour and $2.3(0.6)$ compared with 3.5 $(3 \cdot 3) \% .{ }^{5}$ We confirmed the study of Newell et al that the amount of reflux did not correlate with postconceptional age. ${ }^{5}$ Nevertheless, comparisons with previous studies are of limited value because either $\mathrm{pH}$ recordings were of short duration $^{12}$ or infants received hourly milk feedings. ${ }^{5}$ Milk feeding buffers intragastric $\mathrm{pH}$ and thus appreciably reduces acid GOR during the 120 minute postprandial period. ${ }^{813}$ By contrast, the supine position may have favoured GOR in our patients as has been previously demonstrated in mechanically ventilated preterm infants. ${ }^{12}$

Reproducibility of 24 hour oesophageal $\mathrm{pH}$ studies have been recently questioned beyond the neonatal period. Vandenplas et al concluded that this reproducibility was satisfactory because they found high values for Pearson correlation coefficients when comparisons were performed between $\mathrm{pH}$ recordings on two consecutive days in 30 infants and children. ${ }^{14}$ Nevertheless, Hampton et al stressed the fact that simple correlation of pairs of results does not allow the assessment of the reproducibility of any test. ${ }^{15}$ By analysing the differences between the pairs of results in 13 infants these authors concluded that there was a low reproducibility of $\mathrm{pH}$ monitoring. ${ }^{15}$ Similarly the reproducibility of $\mathrm{pH}$ recording results appeared unsatisfactory for clinical applications in the mechanically ventilated preterm infants. The median of the absolute difference for reflux index was $1 \%$ when the consecutive periods were compared and reached $2 \cdot 5 \%$ when the periods were separated by 96 hours. These findings did not indicate unreliability of the $\mathrm{pH}$ monitoring, the reproducibility of which has been demonstrated in adult patients, ${ }^{16}$ but biological variability.

Compared with the late postprandial periods of the 24 hour $\mathrm{pH}$ recording performed after weaning from the ventilator, the early $\mathrm{pH}$ recording showed an increased number of episodes of GOR and a lower reflux index without any difference in episodes of acid GOR. This study did not allow us to state precisely the mechanism for the increased total number of episodes of GOR in the mechanically ventilated preterm infants. The prevalence of non-acid GOR during the first $\mathrm{pH}$ monitoring might be due to the low gastric secretion rates on the first days of birth. ${ }^{17} 18$

A favourable role for IPPV on the amount of reflux has been previously suggested in preterm infants for two reasons. (1) A decline in acid GOR has been seen in mechanically ventilated infants showing respiratory distress syndrome or bronchopulmonary dysplasia compared with immediate subsequent periods of spontaneous breathing. $^{5} 19$ (2) IPPV with end expiratory pressure was associated with a decline in the 
positive gastro-oesophageal pressure gradient.' However, we did not find any significant correlation between ventilatory pressures and GOR patterns in the first days of mechanical ventilation.

The role of endotracheal aspiration of gastric contents ${ }^{2}$ has been strongly suggested in the pathogenesis of bronchopulmonary dysplasia. ${ }^{3}$ This study has failed to demonstrate any significant correlation between GOR patterns in the lower third of the oesophagus and the total duration of mechanical ventilation. Recordings in the upper part of the oesophagus and in the pharynx could be better indicated in demonstrating a worsening of neonatal pulmonary diseases by GOR.

1 Goodwin SR, Graves SA, Haberkern CM. Aspiration in intubated premature infants. Pediatrics 1985;75:85-8.

2 Valat QC, Bemont F, Pegat MA, et al. Radionuclide study of bronchial aspiration in intensive care newborn children. Nucl Med Commun 1986;7:593-8.

3 Bancalari E. Bronchopulmonary dysplasia. Pediatr Clin North Am 1986;33:1-23.

4 Garo B, Geier B, Boles JM, et al. PHmétrie oesophagienne systématique: quelles sont la fréquence et les conséquences du reflux acide gastro-oesophagien? Réanimation Soin Intensifs et Médecine d'Urgence 1986;2:272.

5 Newell SJ, Morgan MEI, Durbin GM, Booth IW, McNeish AS. Does mechanical ventilation precipitate gastrooesophageal reflux during enteral feeding? Arch Dis Child 1989;64:1352-5.
6 Bhat R, Zikos-Labropoulou E. Resuscitation and respiratory management of infants weighing less than 1000 grams. Clin Perinatol 1986;13:285-97.

7 Newell SJ, Booth IW, Morgan MEI, Durbin GM, McNeish AS. Gastro-oesophageal reflux in preterm infants. Arch Dis Child 1989;64:780-6.

8 Gouyon JB, Boggio V, Athias P, Moreau D, Pujol HP, Spinelli A. Frequency of gastroesophageal reflux in neonates as assessed by 24 -hour $\mathrm{pH}$ monitoring. Helv Paediatr Acta 1986;41:301-10.

9 Paton Y, MacFadyen UM, Simpson H. Sleep phase and gastro-oesophageal reflux in infants at possible risk of SIDS. Arch Dis Child 1989;64:264-9.

10 Herbst JJ. Gastroesophageal reflux. In: Lebenthal E, ed. Textbook of gastroenterology and nutriton in infancy. 2nd Ed. Textbook of gastroenterology and nutriton in

11 Snedecor GW, Cochran WG. Statistical methods. 7th Ed. Ames: Iowa State University Press, 1980.

12 Saint Martin J, Choulot JJ, Leblond C. Etude de la pHmétrie oesophagienne chez le nouveau-né de moins de 1700 grammes. Arch Fr Pediatr 1986;43:249-52.

13 Sutphen JL, Dillard RN. Effects of maturation and gastric acidity on gastroesophageal reflux in infants. $\mathrm{Am} \mathcal{J} \mathrm{Dis}$ Child 1986;140:1062-4

14 Vandenplas Y, Helven R, Goyvaerts H, Sacre L. Reproductibility of continuous 24 hour oesophageal $\mathrm{pH}$ monitoring in infants and children. Gut 1990;31:374-7.

15 Hampton FJ, Mac Fadyen M, Simpson H. Reproductibility of 24 hour oesophageal studies in infants. Arch Dis Child 1990;65:1249-54.

16 Johnsson F, Joelsson BO. Reproducibility of ambulatory oesophageal pH monitoring. Gut 1988;29:886-9.

17 Euler AR, Byrne WJ, Cousins LM. Increased serum gastrin concentrations and gastric acid hyposecretion in the
immediate newborn period. Gastroenterology 1977;72: immediate

18 Hyman PE, Clarke DD, Everett SL, et al. Gastric acid secretory function in preterm infants. $\mathcal{f}$ Pediatr 1985;106:

19 Sindel BD, Maisels MJ, Thomas BCh, Ballantine VN. Gastroesophageal reflux to the proximal esophagus in infants with bronchopulmonary dysplasia. Am $\mathcal{F}$ Dis Cintd 1989;143:1103-6. 